\title{
ENIGE VARIANTE BY DIE WERKWOORD IN DIE HABAKUKKOMMENTAAR
}

Die sogenaamde Habakukkomentaar (H.K.) is een van die manuskripte wat die Bedoeiene in die lente van 1947 in ' $\mathrm{n}$ grot $2 \mathrm{~km}$. van die oewer van die Dooie See af in die Judese gebergte, $1 \mathrm{~km}$. noord van Chirbet Kumran en $12 \mathrm{~km}$. suid van die moderne Jerigo gevind het. Die H.K. is in 'n duidelike kwadraatskrif op goudbruin leer geskryf. Die begin daarvan is erg beskadig. Van kolom 1 ontbreek twee-derdes asook die begin, en van kolom 2 die middel.

Die H.K. bevat nie hoofstuk 3 nie, en aangesien die einde van die rol na binne ingerol was, kon hoofstuk 3 nie afgeskeur het nie. Dié feit gee steun aan die sienswyse van sommige geleerdes dat hierdie hoofstuk nie tot die oorspronklike behoort het nie.

Aangesien die H.K. die teks van Hab. 1 en 2 aanhaal, het dit betekenis vir die tekskritiek. In verskeie opsigte wyk die teks van H.K. van dié van die Masoretiese teks (M.T.) af: scriptio plena waar M.T. scriptio defectiva het en omgekeerd, gebruik van die lidwoord waar dit by M.T. ontbreek en omgekeerd, verskil in gebruik van voornaamwoordelike suffiekse, verskil in gebruik van voorsetsels $\left(2: 13 \mathrm{~m}^{\mathrm{c}} \mathrm{m}\right.$ i.p.v. $\left.m \bar{e}^{\vec{e}} \bar{e} t\right)$ en van woorde (2:5 hôn i.p.v. hajjajin) en skryffoute. Voorts is daar verskeie variante by die werkwoord in die teks.

1. Scriptio plena en scriptio defectiva

(a) Sewemaal het H.K. scriptio defectiva waar M.T. scriptio plena het: 1:10 H.K. rznim, M.T. rôzenim. In die reël skryf die uitlegger die Qal ptc. aktief plene (vgl. 1:12).

1:17 H.K. jḥml, M.T. jaḥmôl hoewel die skrywer andersinds scriptio plena vir Qal imperf. vooropstel.

2:7 H.K. whjtâh, M.T. wehajîtâ. Volgens Elliger (Studien zum Habakuk-Kommentar vom Toten Meer) is die scriptio defectiva hier miskien 'n vergissing; as 3 e persoon enkelvoud vroulik kan die vorm hier kwalik verstaan word. G. R. Driver vertaal dit dan ook met $2 \mathrm{e}$ persoon enkelv. manlik. In 2 Kon. 9:37 het ons hâjițâ (Kețib), hâjetâh (Qerē), terwyl 2 Sam. 15:33 die vorm wehájițâ het (laasgenoemde met net een $\mathrm{j}$ ), sodat genoemde werkwoord in H.K. as $2 \mathrm{e}$ persoon enkelv. manl. te verstaan is. Vir hierdie defektiewe skryfwyse vergelyk ook $2: 13,15 \mathrm{hbt}$ naas M.T. habbitt.

$\mathrm{Hbt}(1: 13 \mathrm{a}, 2: 15)$ ' $\mathrm{n}$ inf. is sonder $\mathrm{j}$ geskryf, terwyl in $1: 3 \mathrm{hbit}$ en $1: 13 \mathrm{~b}$ tabbitu die verwagte $\mathrm{j}$ toon. By ander werkwoorde verskyn die Hif. inf. constr. met $j$. Elliger vra: Het ons hier 'n uitspraak e en nie i nie? In 2:6 kom die woord cbțt naas M.T. cbtit =pandskuld voor. Volgens Gesenius-Kautzsch $53 \mathrm{n}$ is daar waarskynlik 'n misverstand t.o.v. scriptio defectiva soos o.a. Jes. 44:28 jaslim (Jesaja-rol jslim) en is deels bedoel as ' $n$ gemengde vorm om Qal- en Hif.vorme te kombineer. In aansluiting by Elliger se vraag toon ook Birkeland 
(Akzent und Vokalismus im Althebraisschen, 1940) in sy uiteensetting van die Hebreeuse fonologiese vokaalsisteem dat as fonetiese variant van die foneem i e optree.

(b) Hierteenoor het H.K. 39 maal scriptio plena waar M.T. scriptio defectiva het, waarvan sowat die helfte $l \hat{o}=$,nie".

Die Werkwoord

(i) Qal ptc. aktief (4 maal) bv. 2:8 jôšebê, 2:12 bôneh.

(ii) Qal imperf. (2 maal) nl. 1:10 wajjișbôr, 2:1 ' ' môdh.

(iii) Qal inf. constr. (1 maal) nl. 1:17 lah ${ }^{\mathrm{a}}$ rôg.

(iv) Karakteristiek van H.K. is dat ook 'n kort vokaal deur wâw weergegee word: H.K. 1:5 jsûpr terwyl M.T. jesuppar het, 2:4

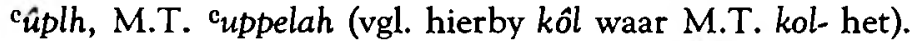

Wat die uitlegteks betref, word soos in M.T. Wâw en Jôd vir natuut- en toonlang-o, u respektiewelik e, ê en i gebruik. Die Qal ptc. aktief is reëlmatig plene geskryf, in enkelvoud en meervoud. Die ô van Qal inf. constr. van sterk- en dubbel-c $A_{j j i n-}$ werkwoorde is reëlmatig deur Wâw weergegee en so ook infinitiewe met suffiekse -ô en -am, dus afwykend van die Masoretiese grammatika, dus waar dit die vorm qe $e^{\hat{t}} \hat{b}$ behou het soos M.T. voor -ka, -kem en -ken bv. ltôfśm waar ons letofśam, ontwikkel uit Oer-Semitiese vorm litufušumu (Birkeland, Nat-Koopmans), in M.T. het. Die sekondêre klemverskuiwing het dus nog nie plaasgevind nie.

Interessant is die ô-imperf. in IV, 6 jşhôqu waar Bybelse Hebreeus slegs 'n $a$-imperf. ken hoewel $\hat{o}$ enkele male in die O.T. as slotvokaal by werkwoorde met 'n laringaal as die eerste konsonant voorkom bv. jinhôm, je'ehôz (G.K. 64c).

2. Verskillende stamformasies van die Werkwoord

(a) 2:7. Hif. jqîsu (Hif. van $q \hat{u} s \underline{s}=$ ontwaak) i.p.v. M.T. Qal jiqșû van $j q s=$ ontwaak. Hier het ons 'n voorbeeld van die verba defectiva (G.K. paragraaf 78). Dit gebeur dikwels dat as twee aanverwante swak werkwoorde in gebruik is met dieselfde betekenis, dat albei defektief is d.w.s. kom nie in al die stamformasies voor nie. Aangesien daardie tye en formasies wat nie in gebruik is nie, in een werkwoord gewoonlik deur 'n ander aangevul word, voltooi hulle wedersyds mekaar, dus jâqaș=ontwaak, slegs in impf. jîqas, in perf. word die Hif. hêqîs gebruik van die wortel qûs (G.K. 78b).

(b) 1:10 Pi. jeqallès i.p.v. M.T. Hitp. jițqallâs=bespot, hoon. Qls Pi. beteken verag, smaad (Eseg. 16:31), met voorsetsel be=bespot, beskimp (Sirag 11:4). Volgens Elliger is die Pi. hoogs onseker en het ons waarskynlik met 'n skryffout te doen; dus geen rede om die M.T. te verander nie. Weliswaar maak die Pi. hier goeie sin. Die Septuagint met lesing metentrufêsei $=$ vir die gek hou, belaglik maak, verleen steun aan albei stamformasies.

(c) 1:11 wajjâsem teenoor M.T. we'âšêm. M.T. „Dan gly hy verby, 'n wind (miskien: soos 'n wind) en trek verder, maar word skuldig, hy wie se krag sy god is." Vir die laaste gedeelte stel O. Procksch (B.H.K., 
derde uitgawe) reeds wesâm kohô le’’lohâw „en hy maak sy krag tot sy $\operatorname{god}(\mathrm{e})$ " wat gesteun word deur H.K., voor, beslis 'n verbetering op die M.T., aldus G. R. Driver. Eienaardig genoeg word in die kommentaar na bêt 'šm verwys wat beteken ,huis van skuld". Was die kommentator bewus van 'n ander teks naas die een voor hom? vra C. L. Taylor (Interpreter's Bible). Die Septuagintlesing exilasetai= bevredig, in rus bring, kom meer met H.K. as met M.T. ooreen, so ook 2:16. Die kommentaar is hier egter op die M.T. gebaseer.

(d) Gebruik van die ptc.

(i) 2:4 ptc. jôšrh (suffieks 3e persoon enkelv. vroul.) i.p.v. perf. jâšerâh maar die ptc. dra nie tot groter helderheid by t.o.v. die teks nie.

(ii) 2:18 mri vir M.T. môreh=Leraar, Hif. ptc. van jrh. Edelkoort (De Handschriften van de Dode Zee) lees mari šâquèr en vertaal ,'n bitterheid van leuens". Elliger verklaar die variant as volg: Moontlik het die uitlegger 'n soort dogmatiese korreksie aangebring terwyl hy die titel môreh net vir die „leraar van geregtigheid" wou reserveer. Moontlik het ons hier 'n skryffout. Opvallend is die defektiewe skryfwyse. Terwyl Lamed-Hê-werkwoorde oorspronklik tot 2 verskillende klasse behoort het nl. LamedWaw- en Lamed- Jêd-werkwoorde (G.K. 75a), kon mri net 'n ortografiese variant van môreh wees, dus mrê, vgl. Fi. inf. constr. in Hos. 6:9 hakk kêh naas hakkkêh (eersgenoemde met Jôd as mater lectonis).

(e) Gebruik van die impf.

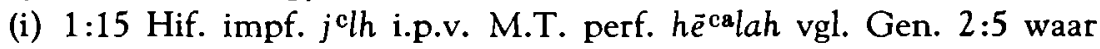
dieselfde impf. gebruik word om 'n voortdurende handeling in die verlede tyd uit te druk (G.K. 107b).

(ii) 2:3 Impf. jfih waar M.T. impf. plus Wâw kopulatief het, dus eenvoudige neweskikking.

(iii) 2:5 Impf. jbgôd i.p.v. M.T. ptc. bôgëd. (Op die ander interessante variante in hierdie vers kan nie hier gewys word nie.)

(iv) 2:12 wjǩnonn i.p.v. wekônēn wat stellig beter is as die M.T., gesien die gebruik van die impf. in vers 13a.

In die M.T. is perf. met Wâw konsekutief gebruik om teenswoordige handelinge uit te druk as die logiese gevolg van handelinge of gebeurtenisse wat voortgaan of herhaal word in die teenswoordige, in hierdie geval na 'n ptc. t.w. bôneh as die ekwivalent van 'n sin wat 'n voorwaardelike handeling uitdruk (G.K. $112 \mathrm{~m}, \mathrm{n}$ ) en die impf. met Wâw kons. wajjekônēen het ongeveer dieselfde betekenis. Ons kan hier ook 'n impf. met $W a ̂ w$ kopulatief hê (vgl. vers 13 wejîtge $\left.^{\mathrm{c}} \hat{u}\right)$ wat veral in lewendige beskrywings gebruik word. In jongere spraakgebruik verdring dit die perf. kons. heeltemal waarvan die H.K. 'n openbaring kan wees (vgl. B. Gemser: Hebreeuse Spraakkuns par. 165). 
(i) 1:15 wjsphû i.p.v. M.T. weja'asefēhû. Volgens Elliger gaan dit by ujsphî om 'n ortografiese eienaardigheid wat met die uitspraak saamhang en dui dit nie op 'n teksvariant nie. Ons vgl. hâsûrim Pred. 4:14 vir ha's sûrim.

(ii) 2:6 wjômrû i.p.v. M.T. wejomèr. Volgens Birkeland was by OudKanaänities die neiging om elke 'Alef aan die sillabeslot te elideer. Teen hierdie neiging het vòò die eindvokaalwegval maar ná die oorgang van $\hat{a}$ na $\hat{o}$ ('Alef kwieësseer in lang $\hat{o}$, dus jo'mar) 'n reaksie ingetree wat deels die deurvoering van die elisie vertraag het, en deels gerestitueerde vorme geskep het.

\section{Enige Gevolgtrekkings}

1. Die verskil t.o.v. scriptio plena en scriptio defectiva by H.K. en M.T. kan o.a. op 'n verskil in uitspraak dui.

2. In geval van inf. plus voornaamwoordelike suffieks het die sekondêre klemverskuiwing nog nie plaasgevind nie, dus lțôfśm vir M.T. letofśam.

3. In sekere opsigte staan die H.K. se teks nader aan die Septuagintteks as aan die M.T.

4. Daar was die moontlikheid dat die kommentator meer as een teks geken het, vergelyk P. Kahle se beskouing i.v.m. 'n „Oerteks” van die O.T.

5. Impf. met $W a ̂ w$ as kopulatief verdring in die jongere spraakgebruik perf. met Wâw konsekutief.

6. Elisie van 'Alef vind plaas in H.K., vergelyk Oud-Kanaänities.

L. M. MUNTINGH.

\section{DIE LIGGING VAN SODOM EN GOMORRA VOLGENS GENESIS 14}

As literêre bron neem Gen. 14 so 'n besondere plek in ${ }^{1}$, dat dit seker nie onvanpas is nie om aan die hand van die geografiese besonderhede wat daarin meegedeel word, die ligging van „Sodom en Gomorra en hulle bure" ${ }^{2}$ te probeer vasstel. ${ }^{3}$ Tot dusver is veral twee streke genoem waar hierdie stede moontlik kon gelê het, nl. ten noord-ooste van die Dooie See ${ }^{4}$ en ten suid-ooste ${ }^{5}$ of benede die suid-oostelike hoek van die Dooie See. ${ }^{6}$ Maar as ons 'n slag die inligting wat Gen. 14 verstrek, selfstandig ondersoek, kom ons tot die gevolgtrekking dat hierdie stede ook nog op 'n ander plek geleë kon wees.

Nadat die dramatis personae in Gen. 14:1-2 voorgestel is, word die aanleidende faktor vir die veldtog wat straks beskrywe sal word, in Gen.14:4 vermeld. Vanaf die vyfde vers begin die beskrywing van die verloop van die veldtog wat kulmineer het in die geveg wat alreeds in vers 3 aangekondig is. In die beskrywing van die veldtog volg die outeur die gebruiklike prosedure soos ons dit ook aantref in ander 